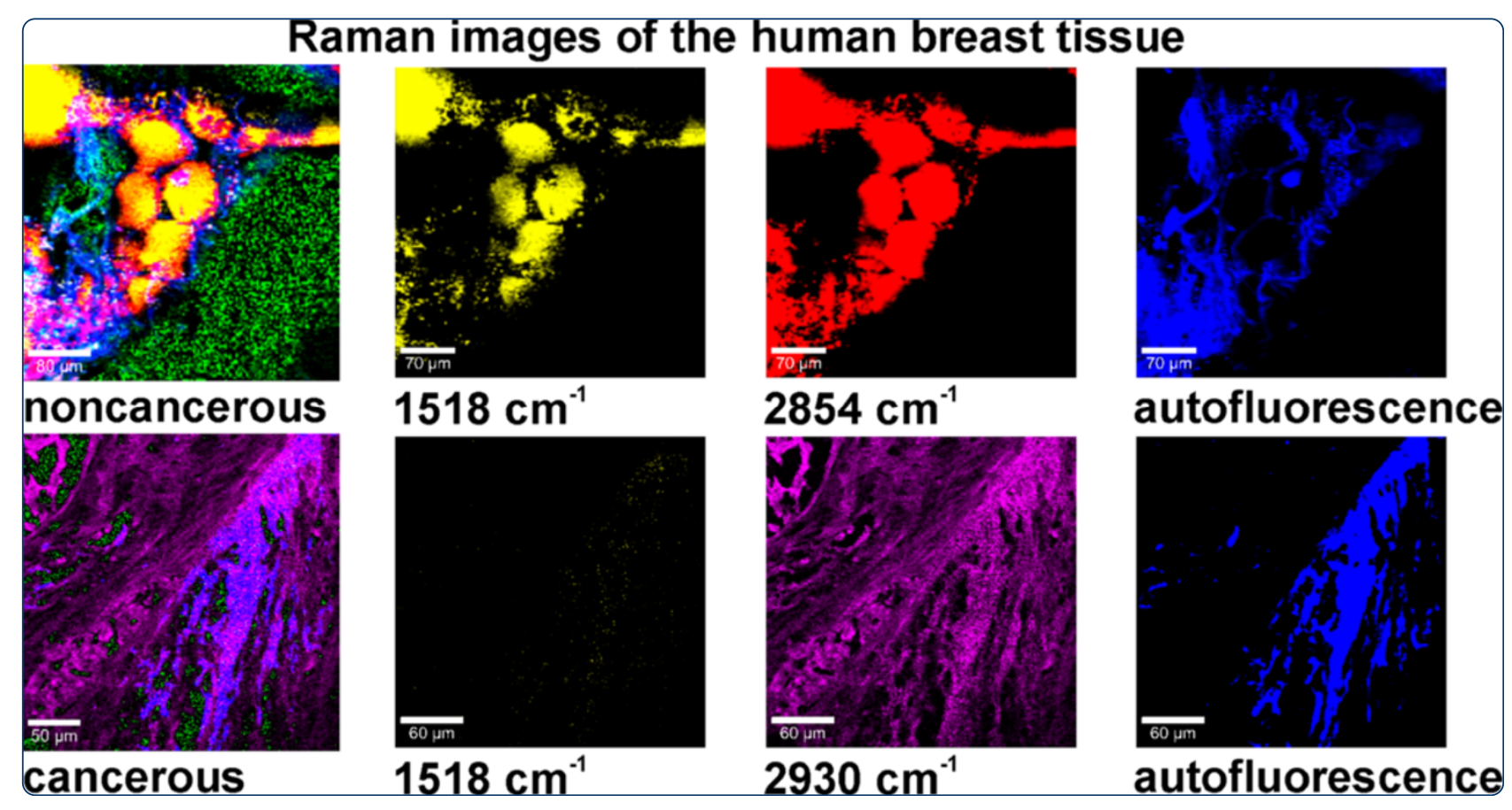

Raman imaging at biological interfaces: applications in breast cancer diagnosis

Surmacki et al. 


\title{
Raman imaging at biological interfaces: applications in breast cancer diagnosis
}

\author{
Jakub Surmacki ${ }^{1}$, Jacek Musial ${ }^{2}$, Radzislaw Kordek ${ }^{2}$ and Halina Abramczyk ${ }^{1 *}$
}

\begin{abstract}
Background: One of the most important areas of Raman medical diagnostics is identification and characterization of cancerous and noncancerous tissues. The methods based on Raman scattering has shown significant potential for probing human breast tissue to provide valuable information for early diagnosis of breast cancer. A vibrational fingerprint from the biological tissue provides information which can be used to identify, characterize and discriminate structures in breast tissue, both in the normal and cancerous environment.

Results: The paper reviews recent progress in understanding structure and interactions at biological interfaces of the human tissue by using confocal Raman imaging and IR spectroscopy. The important differences between the noncancerous and cancerous human breast tissues were found in regions characteristic for vibrations of carotenoids, fatty acids, proteins, and interfacial water. Particular attention was paid to the role played by unsaturated fatty acids and their derivatives as well as carotenoids and interfacial water.
\end{abstract}

Conclusions: We demonstrate that Raman imaging has reached a clinically relevant level in regard to breast cancer diagnosis applications. The results presented in the paper may have serious implications on understanding mechanisms of interactions in living cells under realistically crowded conditions of biological tissue.

Keywords: Breast cancer biochemical imaging, Interfacial water, Raman imaging, IR spectroscopy

\section{Background}

The most important factors in improving the survival rate for cancer patients are: reliable diagnosis for early detection, early treatment, and treatment response monitoring providing with unequivocal data. There is a profound clinical need for diagnostic tools to achieve these goals.

The current diagnosis or prevention methods are based on X-Ray mammography, magnetic resonance imaging (MRI), positron emission tomography (PET) and ultrasonography. X-Ray mammography is the golden standard of imaging examination used for breast cancer diagnosis. However, there are well-known limitations in terms of sensitivity and specificity, especially when scanning patients with high breast density, common in younger women. This leads to relatively unsatisfying levels of false positive and false negative results, as high as $75 \%$ and $34 \%$, respectively [1-3]. Moreover, mammography is not a specific screening method, as it does not allow to differentiate between

\footnotetext{
* Correspondence: abramczy@mitr.p.lodz.pl

'Laboratory of Laser Molecular Spectroscopy, Institute of Applied Radiation Chemistry, Lodz University of Technology, Wroblewskiego 15, Lodz 93-590, Poland

Full list of author information is available at the end of the article
}

benign and malignant tumors. The second standard method - ultrasonography is a fast and low-cost technique, but has a low spatial resolution [4]. The MRI technique offers a good contrast between different soft tissues of the body, but has many drawbacks, like the long duration of the examination and the cost of the instrument. It also causes side effects in the patients like hyperthermia or a negative impact on the patient's kidneys, related to the use of gadolinium contrast agent [5]. Positron Emission Tomography (PET) is an appealing complementary technique for breast imaging, but the image resolution of PET is low and typically ranges between 4 and $7 \mathrm{~mm}$. To improve resolution and contrast between normal and cancerous breast tissue a dedicated breast PET - Positron Emission Mammography (PEM) has been developed [6-8].

To overcome major drawbacks of the standard techniques, the optical methods such as diffuse optical tomography-fluorescence mediated tomography [9,10], photoacoustic imaging [11], acousto-optical imaging [12] have been developed to obtain a more accurate, rapid, inexpensive, and non-destructive method of imaging. The optical imaging systems are ideally suited for early detection of intraepithelial diseases, including most cancers, and allow

\section{Biomed Central}


assessing tumor margins and response to therapy. Optical methods offer several significant advantages over the routine clinical imaging methods, including: a) noninvasiveness through the use of safe, non-ionizing radiation, b) display of contrast between soft tissues based on optical properties of the tissue, c) facility for continuous bedside monitoring, d) high spatial resolution (less than 1 micron lateral resolution in visible range). Almost all of the widely used methods of molecular diagnostics centered on protein separation, amplification, and gene expression in target proteins and nucleic acids involve fluorescence spectroscopy. The confocal, laser-based fluorescence microscopy became a golden standard for optical imaging and molecular diagnostics [13]. The disadvantage of fluorescence is that the multiplexing capability of this technique is limited due to the broad emission profile of fluorophores. This results in difficulty in deconvoluting mixtures of signals.

Raman spectroscopy has many advantages over fluorescence [14]. First, Raman spectroscopy needs no external labeling as the contrast is based on endogeneous optical properties of the biological tissue. The contrast is generated in the cross section for Raman scattering due to induced polarizability generated in the tissue upon irradiation. Raman scattering is inelastic scattering, and measuring the difference between the energy of the incident photons and scattered photons one can obtain the information about vibrations. Therefore, biochemical signatures of the molecules obtained from the Raman spectroscopy are richer than those from the fluorescence spectroscopy. For example-nucleic acids, lipids, biological chromophores and proteins are characterized by narrow vibrational peaks in different spectral regions, in contrast to broad, largely unspecific emission profiles obtained in the fluorescence method. Second, Raman imaging (RI) has now reached a level of sophistication that makes it competitive with more conventional methods of confocal fluorescence microscopy in terms of sensitivity, specificity, and spatial resolution.

Optical Raman imaging has emerged as a new modality which enables real time, non-invasive, high resolution imaging of epithelial tissue, with a particular focus in this paper on breast cancer diagnosis [15-34]. The method has a potential to replace the conventional biopsy and histopathological analysis by an optical Raman biopsy [35-39]. Due to confocal microendoscopy advancements, optically fiber coupled spectrometers and semiconductor technology it becomes possible to perform the in vivo mode of operation in real time.

Raman scattering efficiency can be enhanced by factors $>10^{8}$ when a substance is adsorbed on or near rough metal surfaces. The Raman scattering amplification associated with this phenomenon is known as surface-enhanced Raman scattering (SERS) spectroscopy [40]. These huge increases in Raman scattering are primarily caused by the increased intensity of the electromagnetic fields present at the surface of these metals. SERS preserves the essential features of Raman scattering, yet the surface enhancement provided by the metal nanoparticle allows unique spectra to be acquired from a variety of adsorbed species.

The enhancement can further increase even up to 11 orders and reach a limit of detection of $10^{-16} \mathrm{M}$ in surfaceenhanced resonance Raman spectroscopy (SERRS) [41,42], 13 orders in surface-enhanced Raman scattering-scanning near-field optical microscopy (SERS-SNOM) [31] or even 14-15 orders of magnitude and detection down to $10^{-10}-10^{-14} \mathrm{M}$ in non-linear optical microscopy (e.g. coherent anti-Stokes Raman scattering (CARS)) [43-46].

Therefore, with further advancements of SERS combined with highly sensitive SERS active probes, Raman techniques may open up a new direction in nanomedicine, and bioimaging for high-sensitive high-throughput signal detection, even down to the single-molecule level [44-46].

There is increasing evidence that Raman imaging can be utilized to understand molecular mechanisms of breast cancer $[21,47,48]$. It also has potential to be employed in clinical applications for early diagnosis, recurrence prediction and response to treatment measurement. Properly chosen optically active contrast agents and targeted biomarkers that monitor functional features of cancer can greatly contribute to the development of nucleic acid and protein-based diagnostic tests by Raman methods. The design of proper SERS-based biotags requires a complex interplay of biological interactions for increasing the number of fluorescent proteins or nanoparticles, which is currently at early stages of research and development $[48,49]$.

This paper will focus on new developments in breast cancer biochemical imaging, as well as exploring the potential of clinical applications. The aim of the present study is to demonstrate that the label-free Raman imaging has the ability to accurately characterize breast cancer tissue and distinguish between noncancerous and cancerous types. We will demonstrate how this knowledge contributes to new branches of diagnostic developments for breast cancer diseases. The results presented in this paper demonstrate that Raman imaging has significant potential for probing human breast tissue to provide complementary data in the early diagnosis of breast cancer.

\section{Results}

In this section we present the results of the Raman and IR studies on the noncancerous and cancerous human breast tissues. Having reached this point when we have established the proper protocol of tissue preparation to obtain reliable results from IR and Raman measurements, we will explore vibrational spectroscopy and imaging for a variety of biomedical applications, particularly molecular diagnostics of breast cancer. Details of the protocol are provided in Additional file 1, available at [URL].

Figure $1(A, B, C)$ shows the microscope image, a typical Raman image, and Raman spectra of the noncancerous 

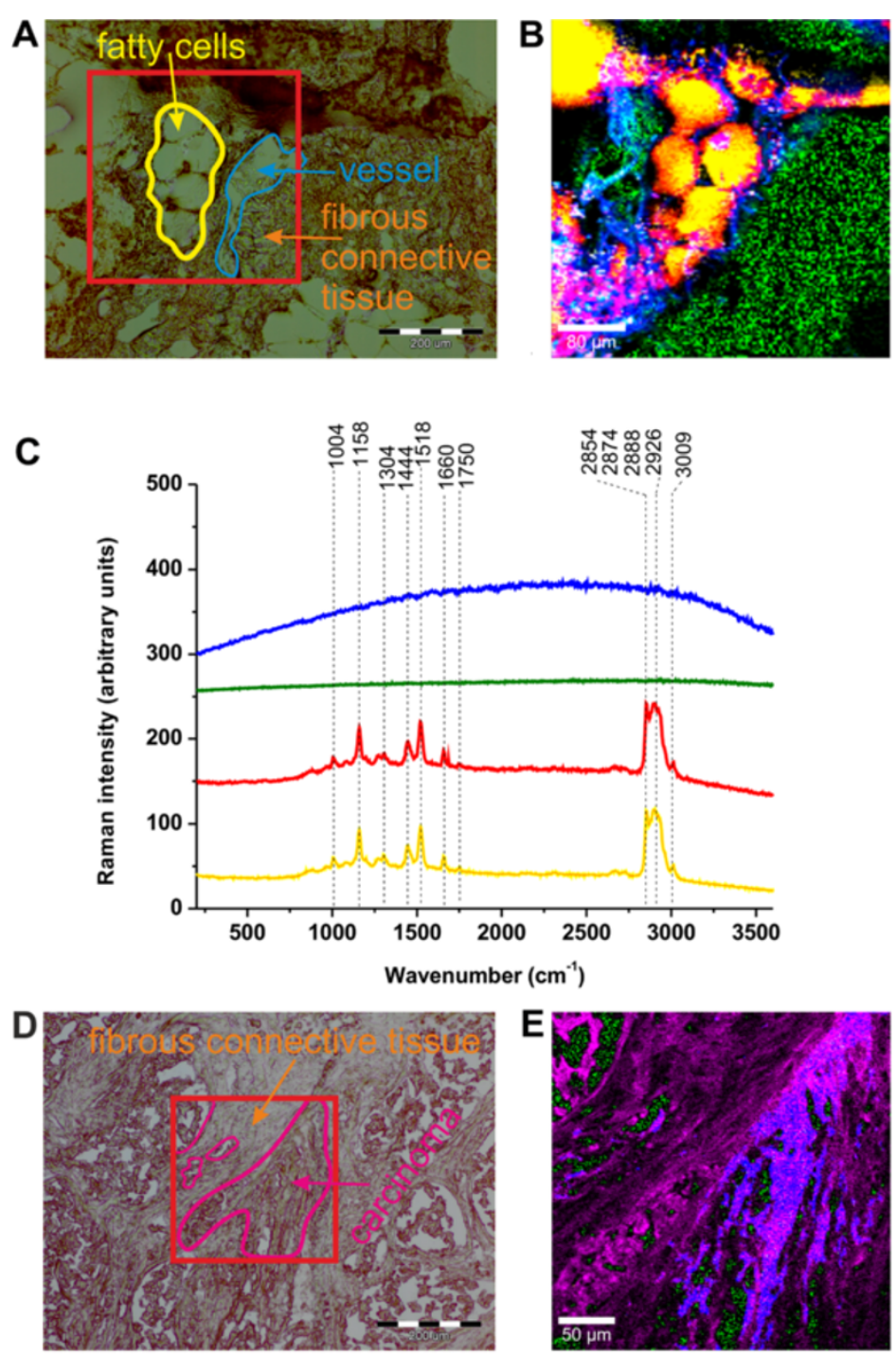

$\mathbf{F}$

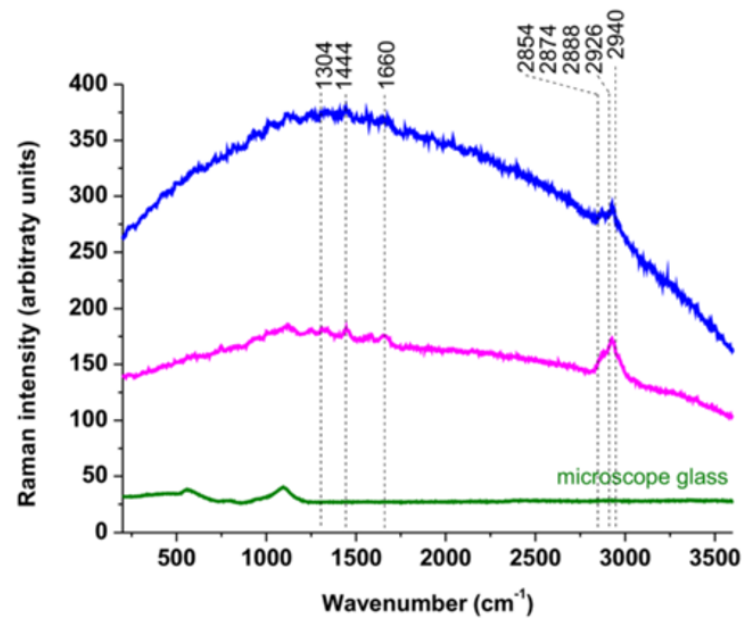

Figure 1 (See legend on next page.) 
(See figure on previous page.)

Figure 1 Raman image and spectra of the noncancerous and cancerous breast tissue of the patient P81. Noncancerous breast tissue: (A) Microscope image, (B) Raman image $(400 \times 400 \mu \mathrm{m})$ from the region marked in (A), (C) Raman spectra (integration time: 0.05 s). Cancerous breast tissue: (D) Microscope image, (E) Raman image $(300 \times 300 \mu \mathrm{m})$ from the region marked in (D), (F) Raman spectra (integration time: 0.036 s). The colors of the spectra correspond to the colors in the image. Mixed areas are displayed as mixed colors.

human breast tissue surrounding the tumor from the safety margin for one of the patients. The total number of patients used in Raman measurements is 200 [15-21]. One can see that the Raman images reveal distinct structures corresponding to inhomogeneous distribution of different compounds in the monitored area. At the first glance, the Raman image (Figure 1(B)) spectacularly resembles a microscope image (Figure 1(A)). The advantage of the 'Raman biopsy' is that it provides direct biochemical information (vibrational fingerprint) in real time and is not prone to subjective interpretations. Moreover, it monitors the biological tissue structures without any external agents, in contrast to histological assessment [18-21].

In order to identify human breast structures and the corresponding biochemical constituents that produce the Raman vibrational pattern of behavior, we have recorded the Raman image for the cancerous breast tissue of the same patient P81. Figure 1(D,E,F) shows the typical microscope image, a Raman image and Raman spectra of the breast cancerous tissue (infiltrating ductal carcinoma) (of the same patient as in Figure $1(A, B, C)$. These Raman spectra have been used as the references basis spectra (see Additional file 1 [URL]) to produce the Raman images.

The first observation that one makes when confronting the results obtained are noticeable differences between the Raman spectra and Raman images of the noncancerous breast tissue surrounding tumor from the safety margin (Figure $1(\mathrm{~B}, \mathrm{C})$ ) and the cancerous breast tissue from the tumor mass (Figure $1(\mathrm{E}, \mathrm{F})$ ). The yellow areas in Figure 1 (B) represent adipose tissue with red areas corresponding to the membranes of the adipose cells filling spaces around the lobules and the ducts. In contrast, the blue and green colors represent strongly autofluorescent structures. The pink and red areas shown in Figure 1(E) represent proteins in the cancerous breast tissue, which are not visible in the normal tissue in Figure 1(B). This finding corresponds to the fact that in contrast to normal cells, the abnormal cells divide in uncontrolled process of cell growth that synthesizes large amounts of proteins.

Significant differences observed in Raman spectra indicate marked distinctions in biochemical composition and distribution of biochemical components. In the next section we will demonstrate that the contrast in Raman images is dominated by carotenoids, fatty acids, proteins and water. We will show that the normal breast tissue surrounding the tumor contains a markedly higher concentration of fatty acids and carotenoids as compared to that of the cancerous tissue. The higher $\beta$-carotene content in normal breast tissue was also found by diffuse reflectance spectroscopy [50]. The cancerous breast tissue has a different profile of vibrational features indicating distinct lipids composition and a much higher contribution from proteins.

\section{Discussion}

In the view of the results presented in the previous section we first need to identify the main biochemical constituents of human breast tissue that contribute to the Raman vibrational pattern of behaviour. Figure 2 shows the typical Raman spectra of the noncancerous tissue, which were obtained from various points of the sample.

The Raman spectra of the noncancerous tissue shows peaks at $877,1004,1158,1304,1444,1518,1660,1750$, 2854, 2888, 2926, and $3009 \mathrm{~cm}^{-1}$. The Raman spectra at 1158 and $1518 \mathrm{~cm}^{-1}$ have been assigned to carotenoids. The bands at 1158 and $1518 \mathrm{~cm}^{-1}$ represent the stretching mode of $\mathrm{C}-\mathrm{C}$ and $\mathrm{C}=\mathrm{C}$ bond of the polyene

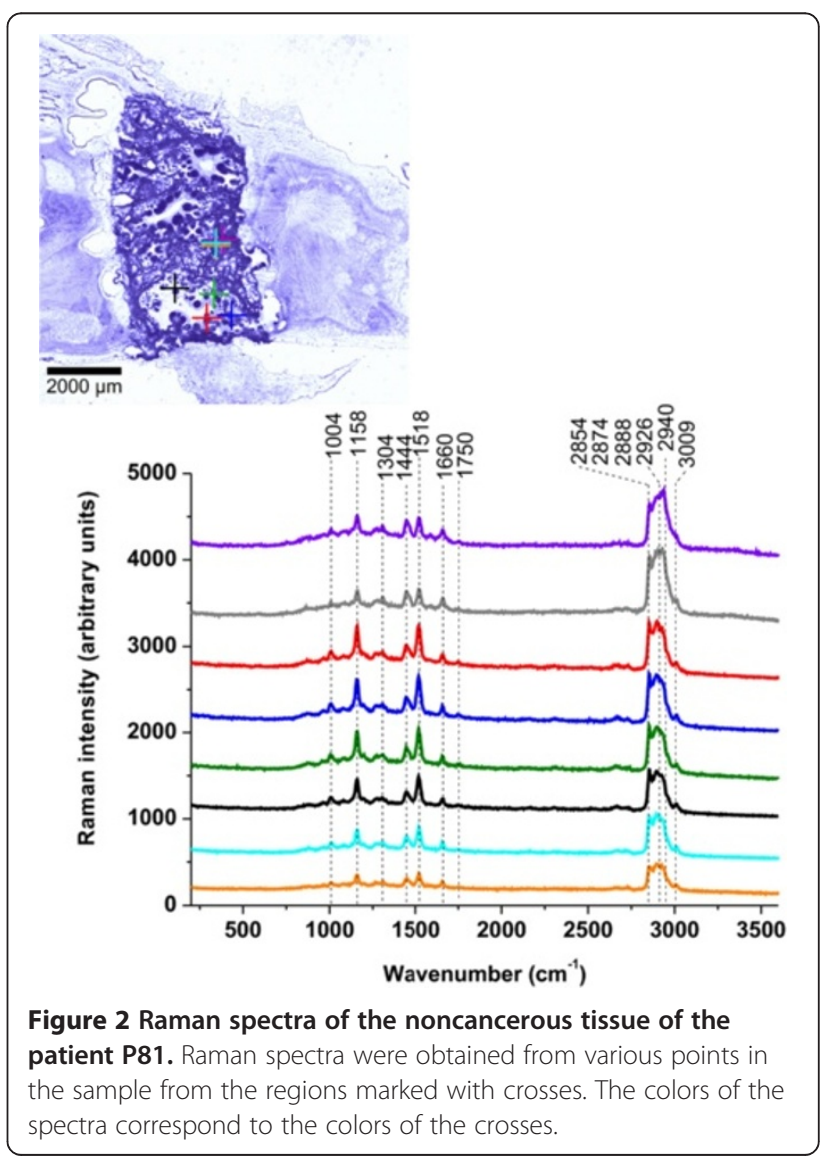


Figure 3 Raman and IR spectra for the noncancerous and cancerous breast tissues (infiltrating ductal carcinoma). (A) Raman spectra of the patient P81; (B) IR spectra of the patient P83; (C) Raman spectrum for the noncancerous normal breast tissues of the patient P81 and IR spectrum for the noncancerous normal breast tissues of the patient P83; (D) Raman spectrum for the cancerous breast tissues of the patient P81 and IR spectrum for the cancerous breast tissues of the patient P83.

chain in carotenoids $[20,21]$. The Raman peaks at 1444 , 1660, 1750, 2854, 2888, 2926 and $3009 \mathrm{~cm}^{-1}$ have been assigned to fatty acids of the adipose tissue contained in the normal breast structure. The comparison with the Raman spectra of the essential fatty acids $\omega-3$ and $\omega-6$ shows that the normal tissue is dominated primarily by oleic acid derivatives $[19,21]$. The assignment of the Raman peaks observed in the noncancerous breast tissue is presented in Additional file 1: Table S1 [URL].

Figure 3(A) compares the Raman spectra for the noncancerous and cancerous breast tissues of the patient P81 (infiltrating ductal carcinoma). The cancerous tissue displays only a limited number of Raman peaks at 558, 1098, 1269, 1444, 1660, 2888, 2926, 2940 and $3311 \mathrm{~cm}^{-1}$. The assignment of the Raman peaks observed in the cancerous breast tissue is presented in Additional file 1: Table S2 [URL].

One of the most remarkable aspects of the comparison are marked differences between the Raman spectra of the noncancerous and cancerous tissues. The most pronounced differences can be seen in the biochemical composition and distribution of carotenoids (1158 and $\left.1518 \mathrm{~cm}^{-1}\right)$, lipids $\left(2800-3000 \mathrm{~cm}^{-1}\right)$ and water represented by the $\mathrm{OH}$ stretching band at $3311 \mathrm{~cm}^{-1}$.

To obtain complementary information on vibrational features of the normal and cancerous tissues, it would be very interesting to compare the Raman spectra with IR spectra. Figure 3(B) shows the comparison between the IR spectra of the noncancerous tissue and cancerous breast tissue.

The comparison between the IR results of the patient P83 (infiltrating ductal carcinoma) presented in Figure 3 (B) demonstrates that the vibrational peaks for the noncancerous and cancerous breast tissues are very similar. The differences in Figure 3(B) are related to the magnitudes of absorbance in the region of 2800-3500 $\mathrm{cm}^{-1}, 1740 \mathrm{~cm}^{-1}, 1444 \mathrm{~cm}^{-1}, 972 \mathrm{~cm}^{-1}$.

In the view of the results presented in Figure 3(A) and (B) it is clearly visible that the Raman method demonstrates a markedly higher specificity allowing to distinguishing between the normal and cancerous breast tissues, thus having the potential to be a better diagnostic tool in breast cancer pathology.

In order to rationalize the vibrational features of the cancer pathology monitored by IR and Raman spectroscopy 
we have compared the results for the noncancerous and cancerous breast tissues. Figure 3(C) compares Raman and IR spectra for the noncancerous breast tissues.

A detailed inspection into Figure $3(\mathrm{C})$ demonstrates that the vibrations originating from carotenoids at 1158 $\mathrm{cm}^{-1}$ and $1518 \mathrm{~cm}^{-1}$, which are the strongest signals in the Raman spectrum, are not visible in the IR spectrum. The reason is quite obvious, and that is because the excitation with $514 \mathrm{~nm}$ leads to the resonance Raman enhancement of carotenoids, which is not present in IR measurements. The IR spectra of the noncancerous tissue shows peaks at 1444, 1660, 2854, 2888, $2926 \mathrm{~cm}^{-1}$ just like Raman spectra. Additional peaks at 842, 972, $1116,1240,1560,1740 \mathrm{~cm}^{-1}$ are clearly visible in the IR spectrum. The marked distinctions can be observed in the lipid-protein profiles in the region of $2800-3000 \mathrm{~cm}^{-1}$, where the contribution from the monounsaturated fatty acids that are common constituents of triglycerides of the adipose tissue dominates the Raman spectrum [19] in contrast to the IR spectra that demonstrate a more protein like profile. These differences originate from different selection rules for the Raman spectroscopy and IR spectroscopy. Namely, a change of molecular polarization corresponding to deformation of the electronic cloud around the chemical bound with respect to the vibrational coordinate is required for a molecule to exhibit a Raman signal. In contrast, a change of molecular dipole with respect to the vibrational coordinate is required for a molecule to exhibit an IR signal.

The most pronounced differences can be seen in the region of water represented by the $\mathrm{OH}$ stretching vibrations, a strong IR band at $3348 \mathrm{~cm}^{-1}$ is observed as opposed to the Raman spectrum, where no water signal is present.

Figure 3(D) compares Raman and IR spectra for the cancerous breast tissues. In contrast to the noncancerous tissue the differences are less spectacular. First, the Raman spectra of the cancerous tissue show no signals from carotenoids like IR spectra. Second, the lipid-protein profiles of IR and Raman spectra in the region $2800-3000 \mathrm{~cm}^{-1}$ are similar, unlike in the case of the normal tissue. Third, both Raman and IR spectra demonstrate contribution from water. The apparently single bands are observed at $3348 \mathrm{~cm}^{-1}$ for IR and $3311 \mathrm{~cm}^{-1}$ for Raman, which we have assigned to the $\mathrm{OH}$ stretching mode of water. The main difficulty in interpretation of the Raman (and IR bands) in the region of $3000-3600 \mathrm{~cm}^{-1}$ comes from the fact that location of bands of water may overlap with the $\mathrm{N}-\mathrm{H}$ stretching bands of proteins (amide A at $3365 \mathrm{~cm}^{-1}$ ) and $\mathrm{N}-\mathrm{H}$ stretching vibrations of DNA. The detailed discussion of this assignment has been presented in reference [24]. It is worth emphasizing that the $\mathrm{OH}$ stretching region of water in the breast tissue with the single band differs markedly from that of the bulk water represented by a double structure with the maximum band positions at
$3258 \mathrm{~cm}^{-1}$ and $3410 \mathrm{~cm}^{-1}$ [18]. It indicates that the characteristic vibrational features of water molecules near a biological interface, where the $\mathrm{H}$-bond network gets locally disrupted, differ significantly from those of bulk water due to interactions with the hydrophilic sites of the tissue. Water in the breast tissue is very likely present as interfacial molecules, with one bond hydrogen bonded to some hydrophilic moieties in the tissue (e.g. proteins or lipid head), and the second bond being free (Figure 4(A)) or involved in $\mathrm{H}$-bond interactions with another water molecules (Figure 4(B)) [18]. The single Raman peak at 3311 $\mathrm{cm}^{-1}$ in Figure 3(A) $\left(3348 \mathrm{~cm}^{-1}\right.$ in IR, Figure 3(B)) has been assigned to the stretching vibration of the $\mathrm{OH}$ bond, which is decoupled from the other $\mathrm{OH}$ bond of a water molecule. The mechanism of decoupling is related to breaking of the $C_{2 v}$ symmetry similar to that observed in water diluted in deuterated water, where the HDO species are generated as a result of isotopic exchange. Breaking of the $C_{2 v}$ symmetry comes from nonequivalent interactions of the $\mathrm{O}-\mathrm{H}$ bonds of the water molecules in the biological tissue - one of the $\mathrm{OH}$ bonds interacts with the hydrophilic sites of the tissue (blue $\mathrm{OH}$ bond in Figure 4), the other $\mathrm{OH}$ is almost quasi free and not involved in any $\mathrm{H}$ bond interactions (dry sample in Figure 4(A)-when there is a limited number of water molecules at the interface) or interacts with other water molecules of the H-bond network (wet sample in Figure 4(B))-when there is a sufficient number of water molecules at the interface). This mechanism illustrated in Figure 4 seems to occur for the surface water at biological interfaces.

The important question arises why IR spectroscopy identifies interfacial water in the spectral region of

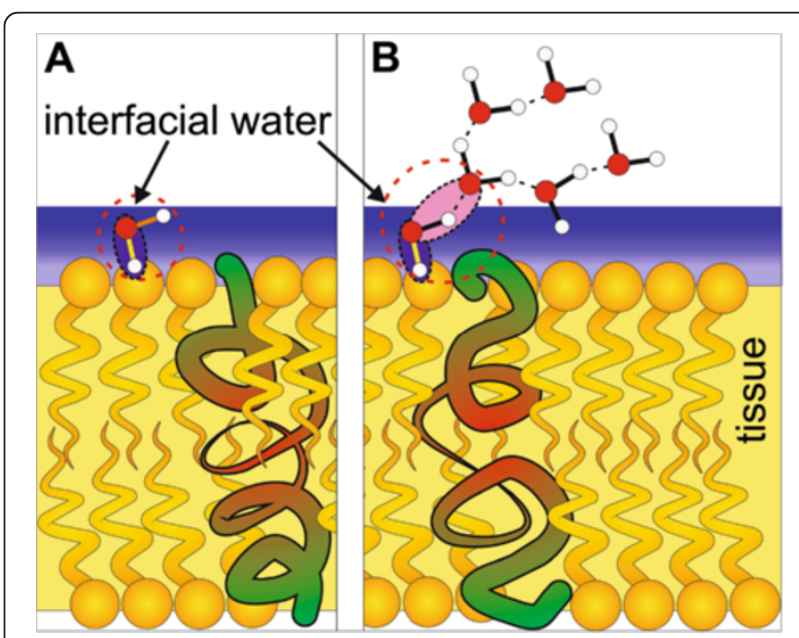

Figure $4 \mathrm{H}$-bond interactions of interfacial water at biological interfaces. (A) dry sample, (B) wet sample; the blue line through the cartoon represents the tissue/water interfaces. The orange and green sites represent the hydrophilic moieties on the surface of the tissue. The red and white circles represent the oxygen and hydrogen atoms in water molecules, respectively. 
$3000-3700 \mathrm{~cm}^{-1}$ both in the noncancerous and in the cancerous tissues (see Figure 3(B) and Additional file 1: Figure S3, [URL]) in contrast to Raman spectroscopy, where only cancerous tissue exhibits vibrational features of water (see Figure 3(A)). It can be explained by the different configurations of the optical paths in Raman and IR techniques (Additional file 1: Figure S1, [URL]). The Raman spectroscopy measures the Raman signal scattered back from the tissue. The IR methods measures the signal transmitted through the tissue thin section attached to the window $\left(\mathrm{BaF}_{2}\right)$. Therefore, the layer of external, ambient water is confined between the tissue section and the surface of the window, giving the contribution to the IR spectrum both in the noncancerous and the cancerous tissues. The ambient water cannot be removed by the reference beam, because the amount of water attached to the empty window differs from that confined under the tissue slice. In the Raman measurements the laser penetration depth is around $30 \mu \mathrm{m}$ at $514 \mathrm{~nm}$ and allows to reaching the layer of water between the microscope glass and the tissue slice of $2 \mu \mathrm{m}$. However, in the confocal Raman microscopy the laser beam is focused exactly on the tissue and the back scattered Raman signal originates only from the tissue. As a result, the Raman signal is dominated by the water molecules confined within the tissue in contrast to the IR signal originating largely from the absorption of water from the space between the tissue and the window (Additional file 1: Figure S1, [URL]).

The detailed inspection into Figure 3(A) shows the spectacular differences in the Raman spectra of the $\mathrm{OH}$ band of water in the noncancerous and cancerous breast tissues. The noncancerous tissue shows a negligible signal of water when compared to the cancerous tissue where the signal peak at $3311 \mathrm{~cm}^{-1}$ is observed. The lack of water is likely due to higher content of hydrophobic adipose tissue in the noncancerous tissue. Indeed, the Raman images presented in this paper show evidently that the breast structure of the noncancerous tissue contains a significantly higher content of the adipose cells (demonstrated in the Raman imaging by the yellow color in Figure 1(B) than the cancerous tissue (Figure 1(E)) that shows negligible amount of the adipose tissue.

In the view of the results presented so far one can state that there are four important Raman markers of breast tissue - carotenoids, fatty acids, proteins and water. Our results demonstrate that there is an intriguing correlation between the amount of monounsaturated fatty acids, carotenoids and water in the breast tissue. First, we will concentrate on the link between carotenoids and monounsaturated fatty acids. Recently, we have shown that oleic acid exists as a separate phase within the noncancerous human breast tissue [19]. The question arises whether we are capable of learning from Raman imaging about areas of the breast tissue structure in which carotenoids and monounsaturated fatty acids are accumulated. Answering this question may be related to the primary mechanisms of carcinogenesis. Several physiological functions have been attributed to carotenoids, particularly an upregulation of gap junctional communication (GJC) in connexins [51,52]. There is growing evidence that the GJC plays an important role in the regulation of morphogenesis, cell differentiation, secretion of hormones, and growth as well as in human diseases including human breast cancer [53].

In order to monitor accumulation of carotenoids and fatty acids in localized regions of the tissue presented in Figures 1(B) and (E) we have employed various spectral filters in the Raman images to analyze different areas of the noncancerous and cancerous breast tissues. Figure 5

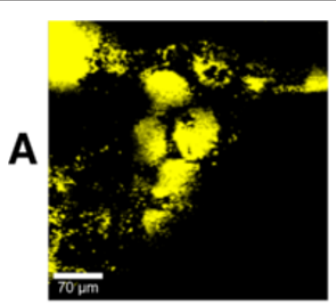

$1518 \mathrm{~cm}^{-1}$

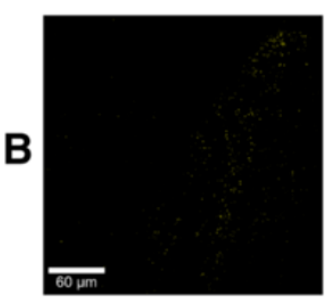

$1518 \mathrm{~cm}^{-1}$

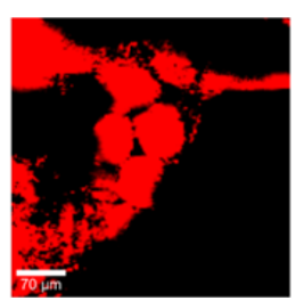

$2854 \mathrm{~cm}^{-1}$

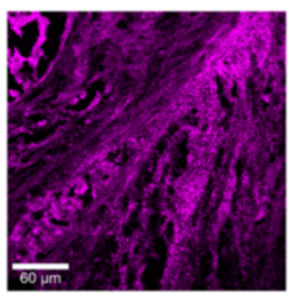

$2930 \mathrm{~cm}^{-1}$

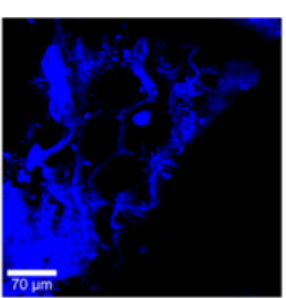

autofluorescence

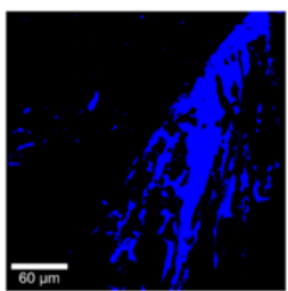

autofluorescence

Figure 5 Raman images. (A) noncancerous and (B) cancerous breast tissue, Filters: carotenoids $\left(1518 \mathrm{~cm}^{-1}\right)$, monounsaturated fatty acids (2854 $\left.\mathrm{cm}^{-1}\right)$, proteins $\left(2930 \mathrm{~cm}^{-1}\right)$ and autofluorescence $\left(1800 \mathrm{~cm}^{-1}\right)$. 

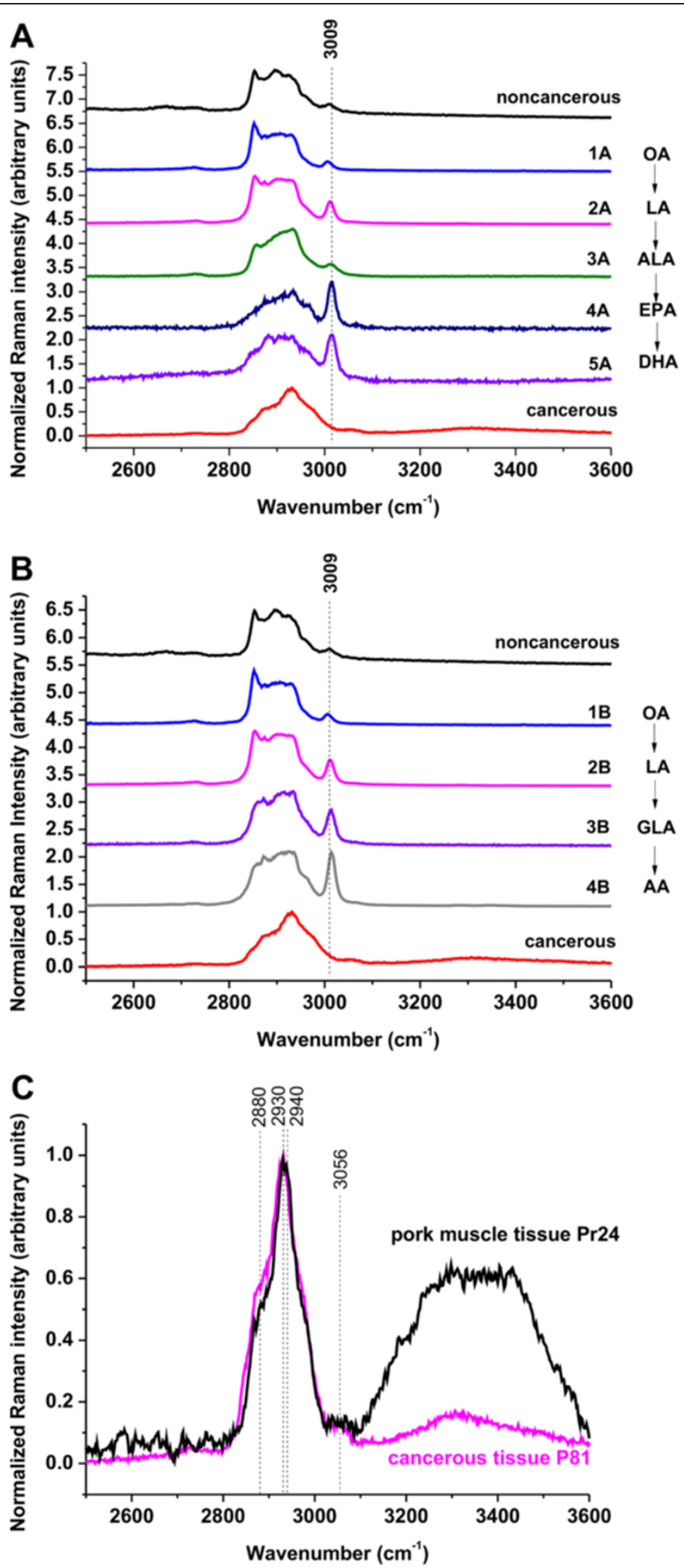

Figure 6 (See legend on next page.) 
(See figure on previous page.)

Figure 6 Raman spectra of fatty acids compared with the Raman spectra of cancerous and noncancerous breast tissues. (A) $1 A$ - oleic acid (OA), 2A - linoleic acid (LA), 3A - a-linolenic acid (ALA), 4A - eicosapentaenoic acid (EPA), 5A - docosahexaenoic acid (DHA), (B) 1B - oleic acid $(\mathrm{OA}), 2 \mathrm{~B}$ - linoleic acid (LA), 3B - $\gamma$-linolenic acid (GLA), 4B - arachidonic acid (AA). (C) Comparison between the Raman spectrum of the cancerous tissue (patient P81) and the spectrum of a muscle tissue from pork meat ( $\operatorname{Pr} 24)$.

shows the Raman images for the noncancerous (Figure 5 (A)) and cancerous (Figure 5(B)) breast tissue for the filters at $1518 \mathrm{~cm}^{-1}, 2854 \mathrm{~cm}^{-1}, 2930 \mathrm{~cm}^{-1}$ and $1800 \mathrm{~cm}^{-1}$ corresponding to the vibrational frequency of carotenoids, oleic acid, proteins and autofluorescence, respectively. One can see that for the noncancerous tissue the Raman image at the filter $1518 \mathrm{~cm}^{-1}$ (Figure 5(A)) illustrating the distributions of carotenoids is almost identical as that for the filter $2854 \mathrm{~cm}^{-1}$ for unsaturated fatty acids and triglycerides. It clearly indicates that the unsaturated fatty acids and triglycerides of the adipose tissue act as a dynamic reservoir that supplies carotenoids to the human organs. In contrast, the cancerous breast tissue does not contain any carotenoids as demonstrated by Figure $5(\mathrm{~B})$ at the filter $1518 \mathrm{~cm}^{-1}$. The pink areas in Figure 5(B) at the filter $2930 \mathrm{~cm}^{-1}$ illustrate the distribution of proteins in the cancerous breast tissue. The comparison of the images of fluorophores in the tissues (at the filter $1800 \mathrm{~cm}^{-1}$ ) in Figure 5(A) and (B) demonstrates that the fluorescent species (blue areas) in the cancerous tissue are accumulated in similar regions as the proteins (pink areas) in contrast to the noncancerous tissue, where the fluorophores are accumulated in the regions complementary to those of the monounsaturated fatty acids and carotenoids (yellow and red areas).

The main difficulty in interpretation of the Raman and IR bands in the region of $2800-3000 \mathrm{~cm}^{-1}$ comes from the fact that the spectral region of the bands of fatty acids and lipids overlap with the bands of proteins. The main protein band near $2940 \mathrm{~cm}^{-1}$ attributed to aromatic and aliphatic amino acids and many other amino acids overlaps with the characteristic $\mathrm{C}-\mathrm{H}$ bands of fatty acids [24] attributed to a variety of $\mathrm{CH}, \mathrm{CH}_{2}$, and $\mathrm{CH}_{3}$ groups in the side chains. Fortunately, a band at $3009 \mathrm{~cm}^{-1}$, corresponding to $\mathrm{H}-\mathrm{C}=\mathrm{C}$ vibrations, which is clearly visible in fatty acids (Figure 6(A,B)), is relatively weak in most proteins and may help to identify dominating components of the tissue in this spectral region.

Figure 6(A,B) compares Raman spectra of selected fatty acids with the Raman spectra of the noncancerous and cancerous breast tissue. Detailed inspection into Figure 6 (A) and (B) shows that the noncancerous tissue contains the $3009 \mathrm{~cm}^{-1}$ vibration typical for fatty acids in contrast to the cancerous tissue that reveals no contribution from $3009 \mathrm{~cm}^{-1}$ component. To check the contribution from proteins we have compared the Raman spectrum of the cancerous tissue with the spectrum of a muscle tissue taken from pork meat, which is dominated by a protein component. Figure $6(\mathrm{C})$ shows the comparison of the Raman spectrum of the cancerous breast tissue of the same patient as in the previous figures with the spectrum of a muscle tissue from pork meat. One can see from Figure 6(B) that the profile of the cancerous tissue is very similar to the protein component with significant contribution of the bands at $2930-2940 \mathrm{~cm}^{-1}$ from proteins and no sign of contribution of the band at $3009 \mathrm{~cm}^{-1}$ from fatty acids. The main band of proteins typically at $2939-2944 \mathrm{~cm}^{-1}$ is due to the aromatic and aliphatic amino acids, the charged amino acids and proline, threonine, and histidine. In contrast to the bands near 2930-2940 $\mathrm{cm}^{-1}$, the bands near 2880 and 3056 $\mathrm{cm}^{-1}$ may reflect predominantly aliphatic and aromatic groups, respectively [54]. The growing contribution from the protein components is a well known indicator of carcinogenesis [55]. Approximately 30\% of breast cancers have an amplification of the HER2/neu gene or overexpression of its protein HER2 product.

\section{Conclusions}

This study has illustrated important aspects of Raman reporters that may be used to characterize human breast tissue at a biochemical molecular level. A number of vibrational features in the $\mathrm{C}-\mathrm{H}$ stretch region change during the process of transformation of the normal breast tissue into the cancerous tissue. These changes may be used to monitor conformational changes of fatty acids, hydrophobic interactions, denaturation, as well as conformational changes of proteins. The biochemical information obtained from the Raman imaging will be particularly useful in monitoring how breast epithelial cells respond to signals from the extracellular matrix (ECM) and how cells lose their normal interactions with the ECM during cancer progression. Raman imaging will help to monitor an increased deposition of ECM proteins and fibroblasts in the stroma surrounding the epithelial cells which is a leading risk factor for breast carcinoma. As a result Raman imaging may help to understand the mechanisms by which stromal density could promote breast carcinoma.

We have found that Raman spectra and Raman images are sensitive indicators of the distribution of main constituents of breast tissue structure such as lipids, proteins, fatty acids, carotenoids and water. The Raman images show evidently that the noncancerous breast tissue contains a significant contribution from triglycerides originating from the adipose tissue filling the spaces 
around the lobules and ducts, and fatty acids that make up the cell membrane and nuclear membrane. The cancerous tissue is dominated by the protein component. We have found that the water amount confined in the cancerous tissue is markedly higher than in the noncancerous tissue. The $\mathrm{OH}$ stretching vibrations of water, $\mathrm{C}-\mathrm{C}, \mathrm{C}=\mathrm{C}$ stretching vibrations of carotenoids, $2930-2940 \mathrm{~cm}^{-1}$ vibrations of proteins, and 2800-3009 $\mathrm{cm}^{-1}$ vibrations of fatty acids can be useful as potential Raman biomarkers to distinguish between the cancerous and the noncancerous human breast tissues. Our results provide experimental evidence for the role played by the lipid-protein-carotenoid profile and cell hydration as factors of particular significance in differentiation of the non-cancerous and cancerous breast tissues.

Our further studies will concentrate on a detailed understanding of interfacial water at the biological surfaces of the cancerous human tissue, where the crowded environment of many biomolecules introduces its own "hydration fingerprint". It is one of the most important topics in molecular biology because it will not only improve our current knowledge about water itself but also lead to significant advances in our understanding of the structure and process with which confined water is associated (protein folding, hydrophobic assemblies, biological membranes).

\section{Methods}

All procedures were conducted under a protocol approved by the institutional Bioethical Committee at the Medical University of Lodz, Poland (RNN/29/11/KE, RNN/30/11/KE, RNN/31/11/KE).

Detailed methodology is available in Additional file 1, available at [URL].

\section{Additional file}

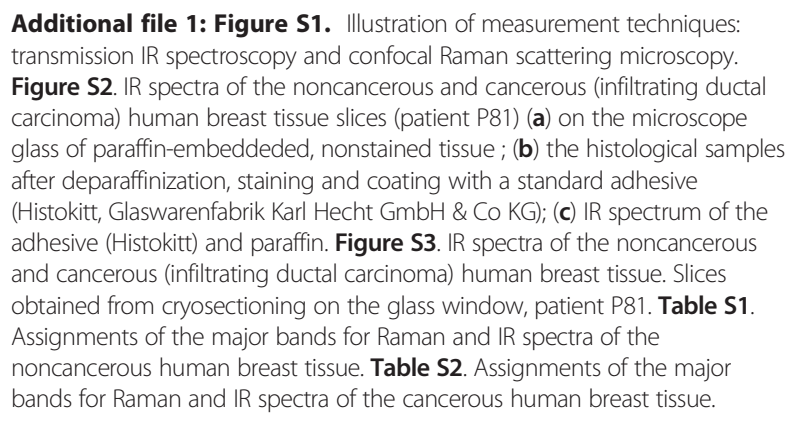

\section{Abbreviations}

IR: infrared; MRI: magnetic resonance imaging; PET: positron emission tomography; PEM: positron emission mammography; Rl: Raman imaging; SERS: surface-enhanced Raman scattering; Microscopy (SERS-SNOM): surfaceenhanced Raman scattering-scanning near-field optical; CARS: coherent antiStokes Raman scattering; DNA: deoxyribonucleic acid; GJC: gap junctional communication; HER2/neu: human epidermal growth factor receptor 2;
OA: Oleic acid; LA: Linoleic acid; ALA: a-linolenic acid; EPA: Eicosapentaenoic acid; DHA: Docosahexaenoic acid; OA: Oleic acid; LA: Linoleic acid; GLA: Ylinolenic acid; AA: Arachidonic acid.

\section{Competing interests}

All authors declare that they do not have any competing interests.

\section{Authors' contributions}

JS performed most of the experiments, analyzed the data, preparing the figures and tables, JM prepared histological samples, examined histological specimens, RK participated in designed carcinogenesis study, HA participated in designed carcinogenesis study, analyzed the data and interpretation of the results. All authors read and approved the final manuscript.

\section{Acknowledgement}

The research work has been financed through the Dz. St. 2013. The authors thank the entire surgical and pathology staff at the Medical University of Lodz and Synevo for their assistance in the research. The authors acknowledge also Dr. Elena Bailo and Dr. Thomas Dieing from WITec (Ulm, Germany) for their technical support and for valuable insights.

\section{Author details}

'Laboratory of Laser Molecular Spectroscopy, Institute of Applied Radiation Chemistry, Lodz University of Technology, Wroblewskiego 15, Lodz 93-590, Poland. 'Department of Pathology, Chair of Oncology, Medical University of Lodz, Paderewskiego 4, Lodz 93-509, Poland.

Received: 19 December 2012 Accepted: 22 May 2013

Published: 24 May 2013

\section{References}

1. Obi N, Waldmann A, Schäfer F, Schreer I, Katalinic A: Impact of the quality assured mammadiagnostic (QuaMaDi) programme on survival of breast cancer patients. Cancer Epidemiol 2011, 35:286-292.

2. Bird RE, Wallace TW, Yankaskas BC: Analysis of Cancers Missed at Screening Mammography. Radiology 1992, 184:613-617.

3. Elmore JG, Barton MB, Moceri VM, Polk S, Arena PJ, Fletcher SW: Ten-Year Risk of False Positive Screening Mammograms and Clinical Breast Examinations. N Engl J Med 1998, 338:1089-1096.

4. Takei J, Tsunoda-Shimizu H, Kikuchi M, Kawasaki T, Yagata H, Tsugawa K, Suzuki K, Nakamura S, Saida Y: Clinical implications of architectural distortion visualized by breast ultrasonography. Breast Cancer 2009, 16:132-135.

5. Le-Petross HT, Shetty MK: Magnetic resonance imaging and breast ultrasonography as an adjunct to mammographic screening in high-risk patients. Semin Ultrasound CT MR 2011, 32:266-272.

6. Avril N, Adler LP: F-18 fluorodeoxyglucose-positron emission tomography imaging for primary breast cancer and loco-regional staging. Radio/ Clin North Am 2007, 45:645-657.

7. Nass SJ, Henderson IC, Lashof JC: Mammography and Beyond: Developing Technologies for the Early Detection of Breast Cancer. Washington, DC: National Academy Press; 2001.

8. Abreu MC, Almeida P, Balau F, Ferreira NC, Fetal S, Fraga F, Martins M, Matela N, Moura R, Ortgao C, Peralta L, Rato P, Ribeiro R, Rodriques P, Santos Al, Trindade A, Varela J: Clear-PEM: A dedicated PET camera for improved breast cancer detection. Radiat Prot Dosim 2005, 116:208-210.

9. Tromberg BJ, Pogue BW, Paulsen KD, Yodh AG, Boas DA, Cerussi AE: Assessing the future of diffuse optical imaging technologies for breast cancer management. Med Phys 2008, 35:2443-2451.

10. Schulz RB, Peter J, Semmler W, D'Andrea C, Valentini G, Cubeddu R: Comparison of noncontact and fiber-based fluorescence-mediated tomography. Opt Lett 2006, 31:769-771.

11. Mienkina MP, Friedrich CS, Gerhardt NC, Beckmann MF, Schiffner MF, Hofmann MR, Schmitz G: Multispectral photo-acoustic coded excitation imaging using unipolar orthogonal Golay codes. Opt Ex. 2010, 18:9076-9087.

12. Ramaz F, Forget BC, Atlan M, Boccara AC, Gross M, Delaye P, Roosen G: Photorefractive detection of tagged photons in ultrasound modulated optical tomography of thick biological tissues. Opt Exp 2004, 12:5469-5474.

13. Denk W, Strickler JH, Webb WW: Two-photon laser scanning fluorescence microscopy. Science 1990, 248:73-76. 
14. Dieing T, Hollricher O, Toporski J: Confocal Raman Microscopy. Dordrecht London New York: Springer Heidelberg; 2011. ISBN ISBN: 978-3-642-12521-8.

15. Abramczyk H, Surmacki J, Brożek-Płuska B, Morawiec Z, Tazbir M: The hallmarks of breast cancer by Raman spectroscopy. J Mo/ Struc 2009, 924-926:175-182.

16. Brożek-Płuska B, Placek I, Kurczewski K, Morawiec Z, Tazbir M, Abramczyk H: Breast cancer diagnostics by Raman spectroscopy. J Mol Liquid 2008, 141:145-148.

17. Abramczyk H, Placek I, Brożek-Płuska B, Kurczewski K, Morawiec Z, Tazbir M: Human breast tissue cancer diagnosis by Raman spectroscopy. Spectroscopy 2008, 22:113-121.

18. Abramczyk H, Brozek-Pluska B, Surmacki J, Jablonska-Gajewicz J, Kordek R: Hydrogen bonds of interfacial water in human breast cancer tissue compared to lipid and DNA interfaces. JBPC 2011, 2:158-169.

19. Brozek-Pluska B, Jablonska-Gajewicz J, Kordek R, Abramczyk H: Phase transitions in oleic acid and in human breast tissue as studied by Raman spectroscopy and Raman imaging. J Med Chem 2011, 54:3386-3392.

20. Abramczyk H, Brozek-Pluska B, Surmacki J, Jablonska J, Kordek R: The label-free Raman imaging of human breast cancer. J Mol Liq 2011, 164:123-131.

21. Abramczyk H, Brozek-Pluska B, Surmacki J, Jablonska-Gajewicz J, Kordek R: Raman 'optical biopsy' of human breast cancer. Prog Biophys Mol Biol 2012, 108:74-81.

22. Santos L, Wolthuis R, Koljenovic S, Almeida RM, Puppels GJ: Fiber-optics probes for in-vivo Raman spectroscopy in the high wavenumber region. Anal Chem 2005, 77:6747-6752.

23. Alfano RR, Liu CH, Sha WL, Zhu HR, Akins DL, Cleary J, Prudente R, Cellmer E: Human breast tissues studied by IR Fourier transform Raman spectroscopy. Lasers Life Sci 1991, 4:23-28.

24. Frank CJ, Redd DCB, Gansler TS, McCreery RL: Characterization of human breast biopsy specimens with near-IR Raman spectroscopy. Anal Chem 1994, 66:319-326.

25. Manoharan R, Shafer K, Perelman RT, Wu J, Chen K, Deinum G, Fitzmaurice M, Myles J, Crowe J, Dasari RR, Feld MS: Raman spectroscopy and fluorescence photon migration for breast cancer diagnosis and imaging. Photochem Photobiol 1998, 67:15-22.

26. Motz JT, Gandhi SJ, Scepanovic OR, Haka AS, Kramer JR: Real-time Raman system for in vivo disease diagnosis. J Biomed Opt 2005, 10:031113-031117.

27. Choo-Smith LP, Edwards HGM, Enditz HP, Kros JM, Heule F, Barr H, Robinson JS, Bruining HA, Puppels GJ: Medical applications of Raman spectroscopy: From proof of principle to clinical implementation. Biopolymers 2002, 67:1-9.

28. Shafer-Peltier KE, Haka AS, Fitzmaurice M, Crowe J, Myles J, Dasari RR, Feld MS: Raman microspectroscopic model of human breast tissue: implications for breast cancer diagnosis in vivo. J Raman Spectroscopy 2002, 33:552-563.

29. Baker R, Matousek P, Ronayne KL, Parker AW, Rogers K, Stone N: Depth profiling of calcifications in breast tissue using picosecond Kerr gated Raman spectroscopy. Analyst 2007, 132:48-53.

30. Owen C, Notingher I, Hill R, Stevens M, Hench L: Progress in Raman spectroscopy in the fields of tissue engineering, diagnostics and toxicological testing. Mater Med 2006, 17:1019-1023.

31. Short KW, Carpenter S, Freyer JP, Mourant JR: Raman spectroscopy detects biochemical changes due to proliferation in mammalian cell cultures. Biophys J 2005, 88:4274-4288.

32. Kneipp J, Tom BS, Kliffen M, Marian MP, Puppels G: Characterization of breast duct epithelia: a Raman spectroscopic study. Vib Spectrosc 2003, 32:67-74.

33. Chowdary MVP, Kumar KK, Kurien J, Mathew S, Krishna CM: Discrimination of normal, benign, and malignant breast tissues by Raman spectroscopy. Biopolymers 2006, 83:556-569.

34. Chowdary PD, Jiang Z, Chaney EJ, Benalcazar WA, Marks DL, Gruebele M, Boppart SA: Molecular histopathology by spectrally reconstructed nonlinear interferometric vibrational imaging. Cancer Res 2010, 70:9562-9569.

35. Saha A, Barman I, Dingari NC, McGee S, Volynskaya Z, Galindo LH, Liu W, Plecha D, Klein N, Dasari RR, Fitzmaurice M: Raman spectroscopy: a realtime tool for identifying microcalcifications during stereotactic breast core needle biopsies. Biomed Opt Exp 2011, 2:2792-2803.

36. Dingari NC, Barman I, Saha A, McGee S, Galindo LH, Liu W, Plecha D, Klein N, Dasari RR, Fitzmaurice M: Development and comparative assessment of Raman spectroscopic classification algorithms for lesion discrimination in stereotactic breast biopsies with microcalcifications. J Biophotonics 2012, 6:371-381.

37. Stone N, Baker R, Rogers K, Parker AW, Matousek P: Subsurface probing of calcifications with spatially offset Raman spectroscopy (SORS): future possibilities for the diagnosis of breast cancer. Analyst 2007, 132:899-905.

38. Stone N, Matousek P: Advanced transmission Raman spectroscopy: a promising tool for breast disease diagnosis. Cancer Res 2008, 68:4424-4430.
39. Saha A, Barman I, Dingari NC, Galindo LH, Sattar A, Liu W, Plecha D, Klein N, Dasari RR, Fitzmaurice M: Precision of Raman spectroscopy measurements in detection of microcalcifications in breast needle biopsies. Anal Chem 2012, 84:6715-6722.

40. Graham D, Faulds K: Quantitative SERRS for DNA sequence analysis. Chem Soc Rev 2008, 37:1042-1051.

41. Zeisel D, Deckert V, Zenobi R, Vo-Dinh T: Near-field surface-enhanced Raman spectroscopy of dye molecules adsorbed on silver island films. Chem Phys Lett 1998, 283:381-385.

42. Chowdary J, Sarkar J, Tanaka T, Talapatra GB: Concentration dependent orientational changes of 2-amino-2-thiazoline molecule adsorbed on silver nanocolloidal surface investigated by SERS and DFT. J Phys Chem 2008, 112:227-239.

43. Jarvis RM, Goodacre R: Characterization and identification of bacteria using SERS. Chem Soc Rev 2008, 37:931-936.

44. Isola NR, Stokes DL, Vo-Dinh T: Surface enhanced Raman gene probe for HIV detection. Anal Chem 1998, 70:1352-1356.

45. Haynes CL, Van Duyne RP: Plasmon-sampled surface-enhanced Raman excitation spectroscopy. J Phys Chem B 2003, 107:7426-7433.

46. Kneipp K, Wang Y, Kneipp H, Perelman LT, Itzkan I, Dasari R, Feld MS: Single molecule detection using surface-enhanced Raman scattering (SERS). Phys Rev Lett 1997, 78:1667-1670.

47. Bailo E, Deckert V: Tip-enhanced Raman spectroscopy of single RNA strands: Towards a novel direct-sequencing method. Angew Chem Int Ed 2008, 47:1658-1661.

48. Wang H, Vo-Dinh T: Multiplex detection of breast cancer biomarkers using plasmonic molecular sentinel nanoprobes. Nanotechnology 2009 20:065101-1-065101-6

49. Cao YC, Jin R, Mirkin CA: Nanoparticles with Raman spectroscopic fingerprints for DNA and RNA detection. Science 2002, 297:1536-1540.

50. Soares JS, Barman I, Dingari NC, Volynskaya Z, Liu W, Klein N, Plecha D, Dasari RR: Diagnostic power of diffuse reflectance spectroscopy for targeted detection of breast lesions with microcalcifications. Proc Nat Acad Sci USA 2013, 110:471-476.

51. Lee SW, Tomasetto C, Paul D, Keyomarsi K, Sager RJ: Transcriptional downregulation of gap-junction proteins blocks junctional communication in human mammary tumor cell lines. Cell Biol 1992, 188:1213-1221.

52. Bertram JS: Induction of connexin 43 by carotenoids: functional consequences. Arch Biochem Biophys 2004, 430:120-126.

53. Kumar NM, Gilula NB: The gap junction communication channel. Cell 1996, 84:381-388

54. El-Bahy GMS: FTIR and Raman spectroscopy study of fenugreek (Trigonella foenum graecum L.) seeds. J App/ Spectrosc 2005, 72:111-116.

55. Olayioye MA: Update on HER-2 as a target for cancer therapy: Intracellular signaling pathways of ErbB2/HER-2 and family members. Breast Cancer Res 2001, 3:385-389.

\section{doi:10.1186/1476-4598-12-48}

Cite this article as: Surmacki et al:: Raman imaging at biological interfaces: applications in breast cancer diagnosis. Molecular Cancer 2013 12:48.

\section{Submit your next manuscript to BioMed Central and take full advantage of:}

- Convenient online submission

- Thorough peer review

- No space constraints or color figure charges

- Immediate publication on acceptance

- Inclusion in PubMed, CAS, Scopus and Google Scholar

- Research which is freely available for redistribution 